\title{
An ESP Textbook Evaluation: The Case of English for Islamic Insight
}

\begin{tabular}{|c|c|}
\hline \multicolumn{2}{|c|}{ 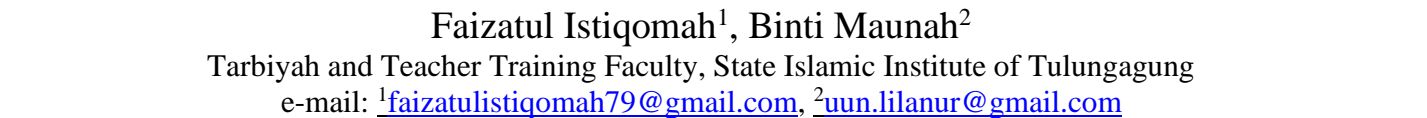 } \\
\hline $\begin{array}{l}\text { Keywords: } \\
\text { ESP; Textbook Evaluation; } \\
\text { English for Islamic Insight }\end{array}$ & $\begin{array}{l}\text { A B S T R A C T } \\
\text { The crucial presence of instructional materials at English classes, } \\
\text { especially English for Specific Purposes, has commonly been } \\
\text { approved. ESP materials provide exposure to the genres needed by } \\
\text { the students, including those at Islamic Education Department. It is, } \\
\text { therefore, inevitable that the textbook meets some criteria for the } \\
\text { success of the program. In this paper, the writers evaluated an ESP } \\
\text { textbook institutionally prepared for students of Tarbiyah and } \\
\text { Teacher Training Faculty at IAIN Tulungagung. The analysis in this } \\
\text { qualitative descriptive research was based on Cunningsworth's and } \\
\text { Miekley's checklists for textbook evaluation. The book was } \\
\text { evaluated on the category of aims and approaches, design and } \\
\text { organization, content, skills, topic, methodology, vocabulary and } \\
\text { grammar, exercises and activities, attractiveness of the text and } \\
\text { physical make up, context, and practical considerations. The results } \\
\text { showed that almost all categories are marked as adequate. It is } \\
\text { indicated that the textbook mainly focused on vocabulary } \\
\text { enrichment. Some recommendations for textbook improvement and } \\
\text { revision are given at the final part of this study, particularly those } \\
\text { related to the challenge on the advanced of technology. }\end{array}$ \\
\hline
\end{tabular}

\section{INTRODUCTION}

The teaching material or a textbook for ESP classes is one essential component for the teacher and students, since the appropriate materials can contribute to the success of ESP program at schools or universities. The materials will be beneficial especially for teachers with less experience in teaching English for specific purposes (Richards, 2001)because as stated by Dudley and Johns (1991), ESP program focuses on specific and identified adult learners which require special materials based on the learners' needs. Those teachers could have adequate competence on the language and pedagogy, yet they may have insufficient contact to the specialized materials needed by the learners. The materials for ESP can be chosen from the available course book, written by the teacher, or modified from the textbook prepared by the institution (Hutchinson \& Waters, 1991). To select one if these three, evaluation is the key to match the criteria of good ESP materials presented by some experts.

Evaluation on ESP textbook is not to judge the excellence or luxury of them but based on 'the degree of fitness for the required purpose' (Hutchinson \& Waters, 1991). The evaluation must consider factors and criteria. Richards (Richards, 2001) mentions five factors to be included in 
the textbook evaluation, such as program, teacher, learner, content, and pedagogical factors. Other experts propose checklists for textbook evaluation, including Hutchinson and Waters (Hutchinson \& Waters, 1991), whose list contains audience, aims, content, methodology, and other criteria; Cunningsworth (Cunningsworth, 1995), who focuses on aims and approaches, design and organization, language content, skills, topic, methodology, teacher's book, and practical consideration; Miekely (Miekley, 2005), whose checklist is divided into three such as textbook, teacher's manual, and context; and Mukundan (Mukundan, Hajimohammadi, \& Nimehchisalem, 2011) who classify the evaluation into general attribute consisting of relation to syllabus and curriculum, methodology, suitability to learners, physical and utilitarian attributes, and supplementary materials, and learning-teaching context which includes general, the four language skills, the three language components, and exercises.

Research on ESP textbooks has been done in many areas and different countries. Among them are Baleghizadeh and Rahimi (Baleghizadeh \& Rahimi, 2011) examining an ESP textbook for sociology students at the University of Tehran, Azarnoosh and Ganji (Azarnoosh \& Ganji, 2015) investigating the textbook of English for management in Iran, Dayane Tous and Haghighi (Dayane Tous \& Haghighi, 2014) evaluating the textbook of English for computer engineering, El-Sakran (El-Sakran, 2012) researching English for Islamic and Arabic Studies textbook in the United Arab Emirate, Fikry (Fikry, 2017) analyzing an EAP course book, which is also included as the branch of ESP (Basturkmen, 2010), Karimnia and Mohammad Jafari (Karimnia \& Mohammad Jafari, 2017) in the case of English for Visual Arts in Iran, Suhirman (Suhirman, 2018) and Syaifullah (Syaifulloh, 2014) in the case of English for Islamic Learning and Islamic Studies at Islamic Higher Education. The last two studies were in Indonesian context.

The textbook being evaluated in this paper is a student's workbook entitled English for Islamic Insight. This book was an institutional prepared material published by IAIN Tulungagung Press in 2017. This book was used to teach English to first semester students of Tarbiyah and Teacher Training Faculty of IAIN Tulungagung (Basuni, Istiqomah, \& Susanto, 2017). The reason for choosing this book is that ESP materials should be qualified to support institution's goal which is to compete globally and listed as one of world class institutes. The researcher is also one of the writers of the book, so this study is also included as self-evaluation or self-assessment one. Further, this book is also selected since the researcher herself was also the teacher who had experience of using this textbook in the class. In this paper, the researchers formulate two research problems, first: has the textbook of English for Islamic Insight met the evaluation textbook criteria proposed by Cunningsworth and Miekley? Second: how has the textbook of English for Islamic Insight met those evaluation textbook criteria?

This study investigated whether the ESP textbook has met the criteria developed by Cunningsworth (1995) and Miekley (2005). In terms of this research limitation, from all items in the checklist, the researchers excluded the items of teacher's books and teacher's manual due to the absence of it used and prepared by the institution. Further, the results was expected to be able to highlight the weaknesses and strengths of this ESP course book, and later to give some recommendations for better materials for the success of ESP program in the future as this study 
is regarded as a preliminary step to gain notes for the ESP material development in the near future at IAIN Tulungagung.

\section{METHOD}

This research employed content or document analysis method with descriptive qualitative approach since the data were the content of an ESP textbook used for university students, the research is intended to identify specific characters of a textbook (Ary, Jacobs, Sorensen, \& Razavieh, 2010), and the researchers described the data not in numbers. The content of the textbook was evaluated using a combination of the checklists developed by Cunningsworth (1995) and Miekley (2005). The evaluation covered 11 categories including: aims and approaches, design and organization, content, skills, topic, methodology, vocabulary and grammar, exercises and activities, Attractiveness of the text and physical make-up, context, and practical consideration. In fact, the combination of checklists contains twelve points but the researcher merge Cunningsworth's language content and Miekley's content into one written as content only. In addition, two criteria regarding teachers' book or manual are excluded from this research because they are not available. Later, four rating scales were utilized to interpret the data in the checklist. The rating scales were excellent $(\mathrm{E})$, good $(\mathrm{G})$, Adequate $(\mathrm{A})$, and poor $(\mathrm{P})$.

\section{RESULTS AND DISCUSSION}

The results of the textbook analysis based on Cunningsworth's (1995) and Miekley's (2005) were described in the sequence stated in the previous section. The results of English for Islamic Insight textbook evaluation are as the following description:

\subsection{Aims and Approaches}

There are eight questions for this first item in the evaluation, relating the aim of the textbook to the aim of the program, teacher's and leaners' need, and also the textbook flexibility. The questions are: Do the aims of the course book correspond closely with the aim of the teaching program? Do the aims of the course book correspond closely with the needs of the learners? Is the course book suited to the learning/ teaching situation? How comprehensive is the course book? Does it cover most or all of what is needed? Is it a good resource for students and teachers? Is the course book flexible? Does it allow different teaching and learning style? The results showed that the textbook met fairly the criteria as it contained materials with specialized language in Islam. Four out of seven chapters of the book discussed the topics on Islam that match the aim of the program and learners' need. However, it terms of flexibility, it did not seem that the book could fully accommodate different teaching and learning style.

\subsection{Design and Organization}

In regard to its design and organization which include questions on the components that make up the total course package, the content organization and sequence, the grading and progression suitability for the learners and allow them to complete the work to meet the syllabus 
requirement, the reference sections for grammar, the material suitability for individual study, the way around the course book, and the lay out. Further, the results show that this textbook was considered good the organization and sequence of texts which were arranged from the short passages at the first parts of the book and ended with the longer ones. Yet, the material was also regarded as poor in the case that this was not appropriate for autonomous learning due to the absence of the answer keys of the exercises and tasks. The grading and progression were also poor at the level of difficulty of the text.

\subsection{Content}

This part contains analysis whether: the subject matter is written topically or functionally in a logical and organized manner, the content consists of learning about the target language culture, the reading texts are authentic, the content challenges the readers' critical thinking on real-life issues, the texts vary sufficiently in genres and sentence structures. Regarding the content, it was found that the subject matter in the book was presented based on the topics, not the functions. In addition, this book did not provide insight about the culture of the target language. The discussion was more on Islam and Indonesia and it seemed that the readers were challenged to relate the contents to their daily-life experience. Some of the reading texts were downloaded from certain website, so they could be considered as authentic materials. The book contained various examples of sentence structures even though it did not represent large range of genres in Islamic studies.

\subsection{Skills}

Cunningsworth's (1995) questions regarding skills within the course book are to figure out if: the book covers all four language skills sufficiently in accordance with the course goals and syllabus, the materials requiring tasks for integrated skills are available, reading texts are adequate, listening materials are authentic and help students' understanding, spoken materials are well designed for real-life communication. Writing tasks are appropriate in styles, control, accuracy, and organization. Thus, it was shown that of the four language skills, this textbook only focused on reading skill with few practices on writing. Every chapter provided adequate materials on reading but the preceding and following activity were on vocabulary enrichment. The material for integrated four skill activity could not be found, and no listening and speaking skill materials were served. In addition, the writing activity was shown at the first and end parts of every chapter in a monotonous style. However, these all skills provided could match students' interests although they may still found difficulty in understanding the texts

\subsection{Topic}

Seven topics were presented within the textbook, including the topics on an Islamic philosopher, 
education in Islam, motivation and achievement, teacher certification, history of Arabic Language, the rights of parents in Islam, and the overview of Indonesia. From these, only one topic discussed women as equal or even superior to men, other topics showed the portrayal of men as a philosopher and teacher and also neutral stands on gender. Therefore, related to the criteria listed in the checklist, it means that the materials sufficiently met students' interests, but only in those seven variations of topics. Those topics may not be able to develop students' awareness and experience on other absent topics on Islamic studies and the culture of the target language. However, these topics are sophisticated enough for students' language level. In addition, since the topics are about Islam, Arabic, and Indonesian contexts, so it should be easier for the learners to relate the materials to their life. Yet, they may have lack of experience and knowledge on other ethnic and occupations.

\subsection{Methodology}

The analysis on methodology includes the language learning approach suitability to teaching and learning situation, expectation on student's active involvement which suits their learning style and expectation, the techniques to introduce new language items, the ways skills are taught, the availability of advice on study skills and learning strategies, and students' responsibility to learn on their own. With regard to methodology, this course book did not focus on communicative language teaching approach. Even though the students are expected to participate actively, yet the activities shown in the book appeared to focus on students individual activities. However, the learners may not be able to be responsible for their own learning easily because they still had to discuss the correct answers with the teachers.

\subsection{Vocabulary and Grammar}

This seventh point of the analysis combines Cunningsworth's (1995) language content and Miekley's (2005) vocabulary and grammar. In this part, the analysis must include the presentation of grammar rules and new vocabulary, the level of difficulty, the techniques to teach them, and the materials on pronunciations. Here, it was apparent that the discussion and practice of grammar exercises were very lacking. The grammar items only appeared twice, in chapter 1 and five, and the rule of grammar discussed was only about pronouns. The first was pronouns as subjects and objects in the sentence, and the last was pronouns as possessive adjective. The latter was even written under the subtopic vocabulary enrichment. There was also no material on pronunciation in the book. On the contrary, a wide range of vocabulary work could be found at every chapter with various kinds of exercises before and after each passage.

\subsection{Exercises and Activities}


The category on exercises and activities contain analysis whether the book include interactive and task-based activities so that students can practice their new vocabulary and grammar items, check that students read the passage to understand them, apply top-down and bottom-up reading strategies and adequate examples on them, and enhance students critical thinking skills on the texts. Then, it was shown that thia ESP textbook is regarded very excellent at providing various exercises not at activities. The exercises on vocabulary and reading comprehension were given in every chapter. The type of the exercises was also varied including true/ false, multiple choice, fill in the blank, short and long answer, etc. Unfortunately, learners were not facilitated to practice the grammar rules in the activity, due to the limited materials on grammar.

\subsection{Attractiveness of the Text and Physical Make-up}

Regarding the aesthetic of the book, the analysis is on its cover and content pages. The picture of the book cover was interesting but not very colorful. It had green and cream background, a small flag of the United State, the title of the book, the writers' and editor's names, publisher's logo, and a picture of a city with a big clock tower in the middle. There were only very few pictures inside the book and the colors were also only black and white. Nevertheless, the texts provided in the book could be enjoyed by the learners even though they did not find great pictures in colors. In addition, ESP is intended for adult learners who might not need much encouragement or motivation on pictures and colors as the young learners did.

\subsection{Context}

This tenth category includes the appropriateness of the textbook to the curriculum, course goals, and learners' needs, level, and interest. It was obvious that the book coincided with the course goal which was to enrich freshman students' vocabulary by providing more exercises on vocabulary and reading texts, but the learning objectives were not stated explicitly in the book. In addition, the content of the book was free from offensive materials, and perhaps this is because the students were homogenous in religion. Therefore, the learners should also enjoy the contents of the book though in reality they might still find the materials too difficult for them since many students learnt English at schools only for the sake of the examination.

\subsection{Practical Consideration}

The last part of the checklist discussed about the price, quality, appearance, and availability of the textbook and whether the book needs other complementary equipment. This ESP textbook was given to students for free because they actually had paid them on the first time they enrolled into the university. However, if students wished to buy, the price was affordable and not very expensive. In terms of appearance, it has been discussed above in the previous category. 6 http://ejournal.uin-malang.ac.id/index.php/JETLe 
Furthermore, this book had standard quality so it was strong enough and lasted longer if students kept them dry. In case of availability, this book was not always available to buy, since the university printed the books in accordance to the numbers of students enrolled in that year. Thus, it could be hard to obtain this book if the stocks were very limited. In addition, this book could be used alone without any additional equipment since the content did not include works or activities requiring the use of specific equipment.

The results above highlighted the strengths and weaknesses of the textbook. This ESP course book was good at its vocabulary enrichment, reading skill practices, and exercises. New vocabulary was provided in the form of various exercises at every chapter preceding the reading texts. The activities following the passages were not only to check students' comprehension but also their understanding on the vocabulary mentioned within the texts. Learners who wanted to improve their vocabulary could benefit more from this book as knowledge on specialized vocabulary is very important for ESP students (Hutchinson \& Waters, 1991) (Basturkmen, 2010). Nevertheless, this result was in contrast to Syaifulloh (Syaifulloh, 2014) that not all of subjects of his study gave positive responses to the vocabulary and reading texts of the ESP book being evaluated. In regard to the reading passages, the texts are considered appropriate to the students' level and interests, and this is in line to the research done by Fikry (Fikry, 2017), Suhirman (Suhirman, 2018), and Dayane (Dayane Tous \& Haghighi, 2014). The texts in the book suited students' need since it contained materials about Islam. In addition, this book also had many different kinds of exercises which encourage students to work with various activities.

However, this book contained drawbacks as the basis for the need of further revision. The weaknesses include the lack engagement on listening and speaking as the materials provided were mostly only on reading and few on writing skills. Azarnoosh and Ganji (Azarnoosh \& Ganji, 2015) also found no change to practice listening and pronunciation. Meanwhile, ESP students should experience learning English in all four skills and three language components such as grammar, vocabulary, and pronunciation. The language skills within the book were also not integrated to each other, while Suhirman's (Suhirman, 2018) results of his study stated that the language skills and components need to be in integration. Secondly, even though the book had met the course curriculum, yet the learning objectives at the beginning of every chapter was absent. Thirdly, this book was in isolation to the technology, whereas in fact students' learning experience should also be integrated to the use of technology (Kern, 2013) as today's life is connected to technology. Fourth, students' active participation, learning autonomy, and responsibility were not emphasized that they seemed to depend on the explanation from the teachers. Fifth is the absence of information on the target language culture. The topics presented in the book were only about Islam and Indonesia. Materials on the culture of the target language could be beneficial for language learners. The final weakness was the availability. Students or teachers or even those who do not study or teach at IAIN Tulungagung but are interested in it could be disappointed if they cannot find this book available at any time they need. 


\section{CONCLUSION}

It can be concluded that the ESP textbook of English for Islamic Insight needs to be improved in almost all aspects listed in the criteria developed by Cunningsworth (1995) and Miekley (2005). The recommendations for improvement are: flexible styles of learning should be part of the consideration; the materials should be graded based on the level of difficulty; contents about different cultures particularly the target culture should be included as language and culture are inseparable; it is obvious that four language skills taught to ESP students should be integrated and should even be integrated to technology by applying blended teaching and learning; students of Tarbiyah and Teacher Training Faculty have to more experience discussing a wide range of themes on Islamic education, thus the materials should include various topics based on students' interests and needs; the approach of the book should consider the communicative language teaching and learning on which students involvement is essential; materials on both vocabulary and grammar should be balanced and cover techniques on problems dealing with the two; the exercises and activities of the book should be varied for all skills and components; the lay out of the materials should be interesting with relevant pictures if necessary; the students' need and the course goal must be revisited; and the textbook should be available at any time. In addition, the availability of teacher's manual seems to be helpful for a more successful ESP program. Regarding the findings of this study, it is suggested to further researchers to take into account the combination of need analysis and ESP course book evaluation to gain more accurate results for better ESP material and course development.

\section{REFERENCES}

Bassnett, Susan. 1993. Comparative Literature A Critical Introduction. UK Blackwell Publisher Freud, Sigmund. 1953. Standard Edition of the Complete Psychological Works of Sigmund Freud. Ed. James Strachey. 24 vols. London: Hogart

Hosseini, Khaled. 2007. A Thousand Splendid Suns. United States: Riverhead Books Publisher http://www.slideshare.net/ericsoncabrera/elements-of-drama. Retrieved on February 2, 2019 at $11 \mathrm{am})$

Morgan,Nicole.http://www.helium.com/items/1210362-violence-in-a-streetcar-named-desire. 2003.

Pervin, L. A, Cervone, Daniel \& John, O. P. 2005. Personality Theory and Research $\left(9^{\text {th }} e d\right)$. United of America: John Wiley

Saddik, Annette J. Contemporary American Drama. Edinburgh: Edinburgh University Press Ltd., 2007.

Vaillant, G. (1994). Ego mechanisms of defense and personality psychopathology. Journal of Abnormal Psychology, 103(1), 44-50 in Peter Muris and Harald Merckelbach. 1997. Suppression and dissociation. Person. indiuid. D\$f , 23( 3), 523-525. 
Williams, Tennessee. 1947. A Streetcar Named Desire. Canada: Penguin Canada Books, Ltd. Yordon, Judy E. 1982. Roles in Interpretation in https://openlibrary.org/search?author_key=OL222795A\&first_publish_year=1982\&has_fulltex $t=$ false \& publisher_facet $=$ Brown $+\% 26+$ Benchmark + Publishers retrieved on February 7, 2019 at $3.10 \mathrm{pm}$ 